\title{
Rotor UMP \& Mechanical Response in HSPMSM in Typical Running Conditions
}

\author{
Yu-Ling $\mathrm{He}$ \\ deptment of Mechanical Engineering \\ North China Electric Power University \\ Baoding, Hebei, China \\ heyuling1@ncepu.edu.cn \\ Peng Gao \\ Sch. of Electrical and Information Eng. \\ Tianjin University \\ Tianjin, China \\ gaopeng218@tju.edu.cn
}

\author{
Gaurang Vakil \\ dept. of Elelctrical \& Electronics Eng. \\ University of Nottingham \\ Nottingham, UK \\ gaurang.vakil@nottingham.ac.uk \\ David Gerada \\ dept. of Elelctrical \& Electronics Eng. \\ University of Nottingham \\ Nottingham, UK \\ david.gerada@nottingham.ac.uk
}

\author{
Xiao-Chen Zhang \\ dept. of Elelctrical \& Electronics Eng. \\ University of Nottingham \\ Nottingham, UK \\ xiaochen.zhang@nottingham.ac.uk \\ Chris Gerada \\ dept. of Elelctrical \& Electronics Eng. \\ University of Nottingham \\ Nottingham, UK \\ chris.gerada@nottingham.ac.uk
}

\begin{abstract}
This paper presents a comprehensive analysis on the rotor unbalanced magnetic pull (UMP) and the consequent mechanical response in 6 typical running conditions in a 20000 rpm high speed permanent magnet synchronous motor (HSPMSM) through finite element analysis (FEA) and experiment. The 6 running cases include normal full-load, normal half-load, normal no-load, static air-gap eccentricity (SAGE) full-load, SAGE half-load, and SAGE no-load. The mechanical responses include the force-caused deformation, the radial vibration, and the dynamic harmonic response due to UMP. It shows that the increment of the load will increase the rotor deformation as well as vibration, and the SAGE case will induce a larger deformation to the rotor and cause a more intensive vibration than the normal condition when with the same load. The harmonic response of the rotor will obtain a max deformation amplitude at $3180 \mathrm{~Hz}$ and $6080 \mathrm{~Hz}$.
\end{abstract}

Keywords-High speed permanent magnet synchronous motor (HSPMSM), unbalance magnetic pull (UMP), static airgap eccentricity (SAGE), mechanical response

\section{ABBREVIATION}

HSPMSM High speed permanent magnet synchronous motor

FEA Finite element analysis

MMF Magnetomotive force

PPUA Permeance per unit area

MFD Magnetic flux density

SAGE Static air-gap eccentricity

\section{NOMENCLATURE}

$g_{0} \quad$ radial air-gap length

$\mu_{0} \quad$ permeability of air and vacuum

$\Lambda_{0} \Lambda_{s} \quad$ Normal PPUA, PPUA component cased by SAGE

$\delta_{s} \quad$ Value of relatively SAGE

$f \quad$ Electrical frequency of HSPMSM

$\omega \quad$ electrical angular frequency

$\alpha_{m} \quad$ mechanical circumferential angle

$I_{a} \quad$ Rotor phase current

$I_{d}, I_{q} \quad \mathrm{~d}$-axis current, q-axis current

$x_{d}, x_{q} \quad \mathrm{~d}$-axis reactance, $\mathrm{q}$-axis reactance

$F_{f} \quad$ rotor MMF

$F_{a}, F_{a 1} \quad$ Stator MMF of full-load \& half-load
$F_{\delta r}, F_{\delta 1}$
composite MMF of full-load \& half-load
$\beta_{f}, \beta_{1}$
$E_{0}$
$\Psi$
$\theta$
$\varphi$
$\varphi$
$B$
angle between composite MMF and rotor MMF
No-load electromotive force
internal power angle (angle between $E_{0}$ and $I_{a}$ )
Power angle (angle between $E_{0}$ and $U$ )
Power factor angle (angle between $U$ and $I_{a}$ ) MFD

\section{INTRODUCTION}

The HSPMSM, which is expected to be more available and meanwhile with less noise by both aircraft operators and aerospace industry, is a key component of the aircraft [1]. In addition to the aerospace field, HSPMSM is widely used in many engineering applications as well. To reduce the noises and vibrations of the rotor, typically, scholars developed magnetic bearings for less friction and energy loss [2]. During the design and manufacturing of the HSPMSM, researchers paid much attention to the electromagnetic properties as well as the cooling problems [2-6], while magnetic forces and vibrations have attracted much less attention. However, the severe UMP on the rotor will cause intense vibrations and noises [7], and also lead to over stresses to the rotor which may damage rotor components [8].

As the increment of the rotating speed and the capacity of the motor, the vibration problem in the high speed motors has become a critical issue [9]. Sumit Singhal et al. studied on the effects of laminated core on the rotor mode shapes, and found that the modal characteristics of the shaft are significantly different from the rotor core as it leads to stiffening of the system and also influences the location of nodes [10]. Chun Gan et al. investigated the effect of skewing the stator and/or rotor on the vibration reduction of the three-phase switched reluctance motors, and finally found that skewing the stator is more effective than skewing the rotor [11]. Sungyong Shin et al. proposed an improved two-step commutation control method to reduce the noise and vibration in switched reluctance motor [12]. Cristian Babetto et al. found that the shape of the rotor is pretty significant for the vibration control [13].

In this paper, a comprehend study including theoretical UMP analysis, finite element calculation, and experimental test for the numerical forces and mechanical responses, is carried out. The remainder of this paper is organized as follows. Section II analyzes the mechanics model of the rotor 
as well as the exciting UMP acting on the rotor, while Section III carries out the finite element calculation and the experimental test on UMP and the mechanical responses. In Section IV, primary conclusions are drawn up and further work in next step is illustrated.

\section{THEORETICAL MODEL}

\section{A. Structure and Equivalent Mechanics Model of Rotor}

The rotor is composed of the rotor core, the shaft, the permanent magnets, the sleeve, and the supporting part. Taking the prototype HSPMSM which will be studied in this paper as an example, the general structure of the rotor is indicated in Fig.1. The rotor core and the sleeve are the parts to hold the permanent magnets, while the supporting part is the component to hold the rotor and the shaft.

Since the physical structure of the rotor is a solid cylinder which is fixed by the bearings, the equivalent mechanics model of the rotor is a simply supported beam which can rotate about $\mathrm{z}$ axis, see Fig.1 (b). The exciting forces are the UMP $F_{x}$ and $F_{y}$, as indicated in Fig. 1 (c), where $K_{x}$ and $K_{y}$ are the elastic/stiffness coefficient in $\mathrm{X}$ - and $\mathrm{Y}$ - direction, respectively, $D_{x}$ and $D_{y}$ are the damping coefficients, and $x_{x}$ and $x_{y}$ are the movements. Usually they are written in matrix forms to formulate the kinetic equation, see Section D.
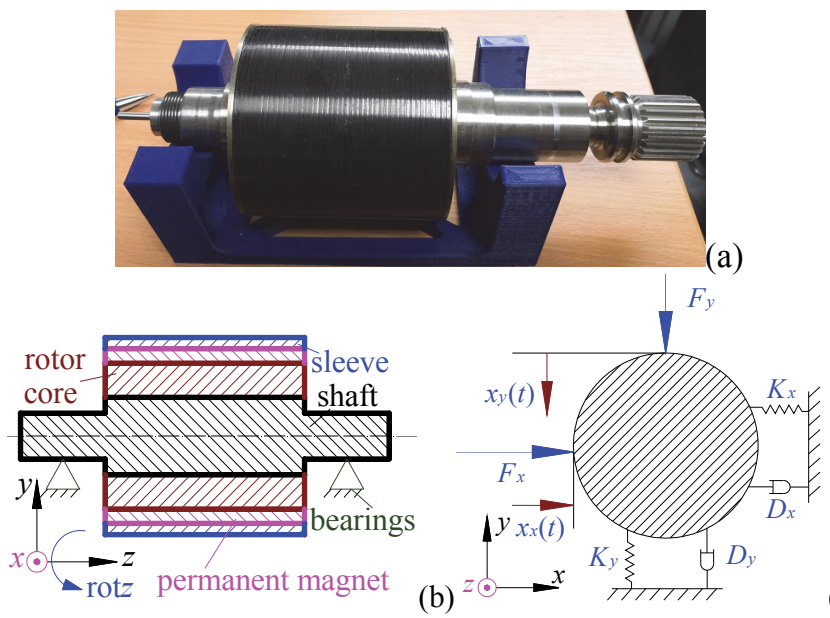

Fig. 1. Rotor structure and mechanics model: (a) picture of prototype rotor, (b) structure diagram, and (c) mechanics model

\section{B. MFD in Typical Conditions}

Due to different running conditions, MMF and PPUA will vary and therefore MFD will be changed, leading to different UMPs on the rotor. Given that most motors has static air-gap eccentricity (SAGE) at different extents, in this paper we investigate 6 typical running conditions, namely the normal full-load case, the normal half-load case, the normal no-load case, the SAGE full-load case, the SAGE half-load case, and the SAGE no-load case.

MMFs in different conditions can be illustrated as Fig.2, where $F_{f}$ is the rotor MMF, $F_{a}$ and $F_{a 1}$ are the stator MMF in full-load and half-load condition, respectively, and $F_{\delta}$ and $F_{\delta 1}$ are the composite MMF of full-load and half-load, respectively.

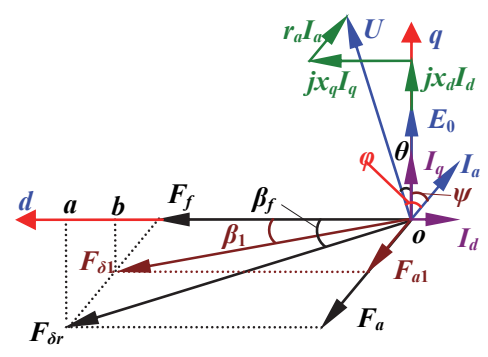

Fig. 2. Space-time phasor diagram of HSPMSM

As indicated in Fig. $2, F_{a 1}$ is about half of $F_{a}$ since in the half-load case the stator current is generally the half of the full-load current. Consequently, $F_{\delta 1}$ is smaller than $F_{\delta .}$ In noload condition, the stator current is very small (only to compensate the energy loss), and the composite MMF is almost equal to $F_{f}$ which is even smaller than $F_{\delta 1}$. Then the composite MMF in full-load, half-load, and no-load condition can be written as

$$
F_{\delta}\left(\alpha_{m}, t\right)=\left\{\begin{array}{l}
F_{f} \cos \left(\omega t-\alpha_{m}\right) \cdots \cdots \cdots \cdots \cdot \text { no-load } \\
F_{\delta r} \cos \left(\omega t-\alpha_{m}+\beta_{r}\right) \cdots \cdots \cdots \cdot \text { full-load } \\
F_{\delta 1} \cos \left(\omega t-\alpha_{m}+\beta_{1}\right) \cdots \cdots \cdots \text { half-load }
\end{array}\right.
$$

where

$$
\left\{\begin{array}{l}
F_{\delta 0} \approx F_{f} \\
F_{\delta r}=\sqrt{\left(F_{r}+F_{a} \sin \psi\right)^{2}+\left(F_{a} \cos \psi\right)^{2}} \\
F_{\delta 1}=\sqrt{\left(F_{r}+0.5 F_{a} \sin \psi\right)^{2}+\left(0.5 F_{a} \cos \psi\right)^{2}} \\
\beta_{r}=\arctan \frac{F_{a} \cos \psi}{F_{r}+F_{a} \sin \psi} \\
\beta_{1}=\arctan \frac{0.5 F_{a} \cos \psi}{F_{r}+0.5 F_{a} \sin \psi}
\end{array}\right.
$$

PPUA can be obtained through the reciprocal of the radial air-gap length

$$
\Lambda\left(\alpha_{m}\right)=\frac{\mu_{0}}{g\left(\alpha_{m}\right)}
$$

The radial air-gap length in normal condition and SAGE case is illustrated in Fig. 3 and can be written as

$$
g\left(\alpha_{m}\right)=\left\{\begin{array}{l}
g_{0} \cdots \cdots \text { normal condition } \\
g_{0}\left(1-\delta_{s} \cos \alpha_{m}\right) \cdots \text { SAGE }
\end{array}\right.
$$

Feed Eq.(4) into (3) PPUA can be obtained

$$
\Lambda\left(\alpha_{m}\right)=\left\{\begin{array}{l}
\mu_{0} / g_{0}=\Lambda_{0} \ldots \ldots \ldots \ldots \ldots \ldots \ldots \ldots \text { normal condition } \\
\frac{\mu_{0}}{g_{0}\left(1-\delta_{s} \cos \alpha_{m}\right)}=\Lambda_{0}\left(1+\delta_{s} \cos \alpha_{m}+\delta_{s}^{2} \cos ^{2} \alpha_{m}+\cdots\right) \\
\approx \Lambda_{0}\left(1+\delta_{s} \cos \alpha_{m}\right)=\Lambda_{0}+\Lambda_{s} \cos \alpha_{m} \ldots \ldots \ldots \ldots \text {. } \ldots \text { AGE }
\end{array}\right.
$$

where in the SAGE case it is expanded by Power Series. It is suggested that the PPUA amplitude in SAGE case will be larger than the normal one, because $\delta_{s}^{2} \cos ^{2} \alpha_{m}=0.5 \delta_{s}^{2}\left(1+\cos 2 \alpha_{m}\right)$ and this lead to the DC component $\Lambda_{0}\left(1+0.5 \delta_{s}^{2}\right)$ obviously larger than $\Lambda_{0}$. 


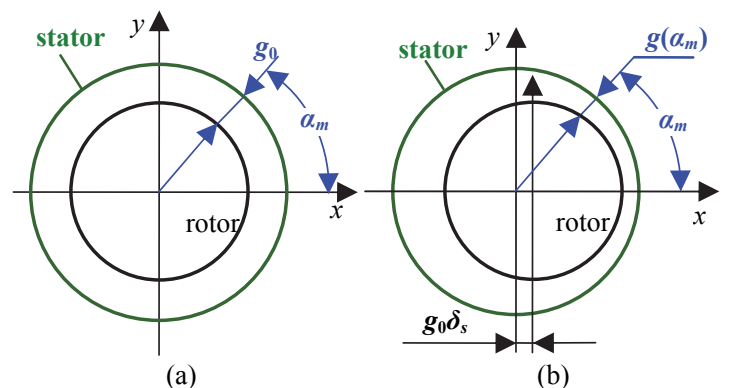

Fig. 3. Air-gap in (a) normal condition, (b) common SAGE case

Finally, MFD can be quickly obtained and written as

$$
\begin{aligned}
& B\left(\alpha_{m}, t\right)=F_{\delta}\left(\alpha_{m}, t\right) \Lambda\left(\alpha_{m}\right)
\end{aligned}
$$

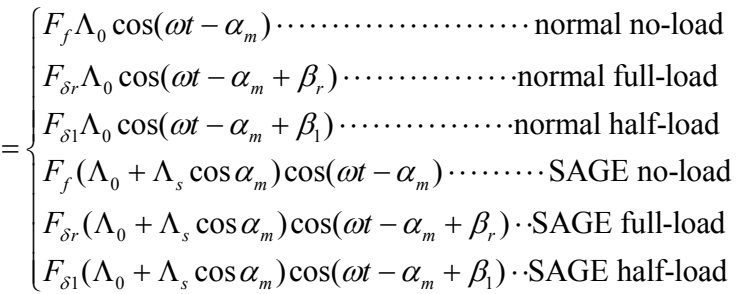

Qualitatively, according to Fig.2 and Eqs. (5) and (6), the MFD amplitude varies in the following orders

No.1: SAGE full-load (the largest)

No.2: normal full-load

\section{No.3: SAGE half-load}

No.4: normal half-load

\section{No.5: SAGE no-load}

No.6: normal no-load (the minimum)

\section{UMP on Rotor in Typical Conditions}

The rotor UMPs in $\mathrm{X}$ and $\mathrm{Y}$ direction can be calculated through

$$
\left\{\begin{array}{l}
F_{X}=L R \int_{0}^{2 \pi} q\left(\alpha_{m}, t\right) \cos \alpha_{m} d \alpha_{m} \\
F_{Y}=L R \int_{0}^{2 \pi} q\left(\alpha_{m}, t\right) \sin \alpha_{m} d \alpha_{m} \\
q\left(\alpha_{m}, t\right)=\frac{B\left(\alpha_{m}, t\right)^{2}}{2 \mu_{0}}
\end{array}\right.
$$

where $B$ is the magnetic flux density (MFD) in the air-gap, $t$ denotes the time, and $\alpha_{m}$ is the mechanical angle to indicate the circumferential position of the air-gap, as indicated in Fig. 2. MFD can be obtained by multiplying the magnetomotive force (MMF) by the permeance per unit area (PPUA).

Feed Eq.(6) into (7) it finally has

$$
\begin{aligned}
& F_{X}=\left\{\begin{array}{l}
0, \ldots \ldots \ldots \ldots \ldots \ldots \\
L R F_{f}^{2} \pi\left[2 \Lambda_{0} \Lambda_{s}+\Lambda_{0} \Lambda_{s} \cos (2 \omega t-2 \beta)\right] / 4 \mu_{0} \cdot \text { SAGE full load } \\
L R F_{\delta}^{2} \pi\left[2 \Lambda_{0} \Lambda_{s}+\Lambda_{0} \Lambda_{s} \cos (2 \omega t-2 \beta)\right] / 4 \mu_{0} \cdot \text { SAGE half load } \\
L R F_{\delta 1}^{2} \pi\left[2 \Lambda_{0} \Lambda_{s}+\Lambda_{0} \Lambda_{s} \cos (2 \omega t-2 \beta)\right] / 4 \mu_{0} \cdot \text { SAGE no load }
\end{array}\right.
\end{aligned}
$$

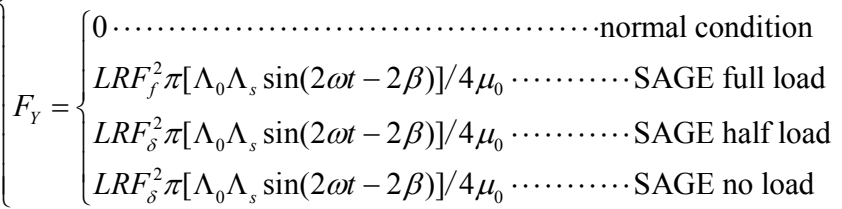

According to Eqs.(7) and (8), the UMP in normal condition is zero, while in SAGE cases the UMPs have the same amplitude rank order as MFD. As indicated in Eq.(8), ignoring the higher order harmonics, the UMP has only the DC component and the pulsating components at $2 f$. However, if taking the higher MMF order harmonics (3rd, 5th, 7th, etc.) into account, the UMP on the rotor should have each even harmonic.

\section{Mechanical Response Analysis}

As indicated in Fig. 1(c), the vibration in X direction and $\mathrm{Y}$ direction can be treated as the periodic movement in these two directions, respectively. The kinetic equation for the rotor can be written as

$$
\left\{\begin{array}{l}
M \dot{x}_{x}(t)+D_{x} \dot{x}_{x}(t)+K_{x} x_{x}(t)=F_{x}\left(\alpha_{m}, t\right) \\
M \ddot{x}_{y}(t)+D_{y} \dot{x}_{y}(t)+K_{y} x_{y}(t)=F_{y}\left(\alpha_{m}, t\right)
\end{array}\right.
$$

where $\boldsymbol{M}$ is the mass matrix of the rotor rotor, $\boldsymbol{D}_{\boldsymbol{x}}$ and $\boldsymbol{D}_{\boldsymbol{y}}$ are the damping matrix in $\mathrm{X}$ direction and $\mathrm{Y}$ direction, respectively, $\boldsymbol{K}_{\boldsymbol{x}}$ and $\boldsymbol{K}_{\boldsymbol{y}}$ are the stiffness matrix in X direction and $\mathrm{Y}$ direction, respectively, $F_{x}\left(\alpha_{m}, t\right)$ and $F_{y}\left(\alpha_{m}, t\right)$ are the exciting load matrixes, i.e., the UMP in $\mathrm{X}$ direction and $\mathrm{Y}$ dierection, respectively, and $x_{x}(t)$ and $x_{y}(t)$ are the displacement response matrix of the structural mass points in $\mathrm{X}$ direction and $\mathrm{Y}$ direction, respectively.

According to the correlation principle between the exciting force and the mechanical response, the vibration should have the same frequencies as the exciting forces. For example, if the pulsating frequency of the exciting force is $2 f$, then, the rotor/rotor will vibrate at $2 f$ as well.

If taking the higher-order MMF harmonics into account in addition to the 1st harmonic indicated in Eq.(2), the rotor vibrations should have each even harmonics, with the 2 nd harmonic as the primary component. Comparing the formulas for each condition in Eq.(8), it can be found that in the SAGE cases, the amplitude of the 2nd-harmonic UMP will be increased as the load rises. As the increment of SAGE, $\Lambda_{s}$ will be increased, and the 2 nd vibration amplitude will also be enlarged.

\section{FINITE ELEMENT CALCULATION AND EXPERIMENT}

\section{A. FEA and Experiment Setup}

The FEA and the experimental work are taken on a 20000 rpm HSPMSM which is indicated in Fig.4 (a), in the University of Nottingham. The primary parameters of the prototype machine are shown in Table I. 


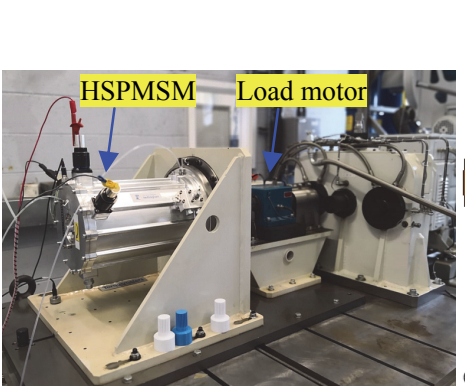

(a)

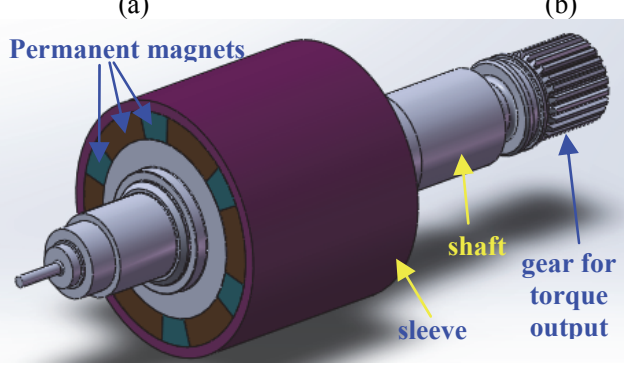

(c)

Fig. 4. FEA model of the prototype HSPMSM: (a) prototype HSPMSM test rig, (b) Halbach Array of PM poles, and (c) 3D model of the rotor.

TABLE I. PARAMETERS OF STUded OBJECT

\begin{tabular}{|c|c|c|c|}
\hline Parameters & Value & Parameters & Value \\
\hline Rated power & $50 \mathrm{~kW}$ & pole-pairs & $p=3$ \\
\hline Conductor per slot & 8 & Winding layers & 2 \\
\hline Fundamental frequency & $f=1000 \mathrm{~Hz}$ & Stator outer diameter & $163 \mathrm{~mm}$ \\
\hline stator slots & 36 & Stator inner diameter & $96 \mathrm{~mm}$ \\
\hline pitch & 5 & Rated phase current & $150 \mathrm{~A}$ \\
\hline Rotor diameter & $92 \mathrm{~mm}$ & Rated rotating speed & $n=20000 \mathrm{rpm}$ \\
\hline Radial air-gap length & $g_{0}=2 \mathrm{~mm}$ & Parallel branches & 1 \\
\hline
\end{tabular}

The PM poles work in the form of Halbach Array, as indicated in Fig.4 (b). The stator winding is loaded with the rated current, the half-rated current, and almost no current to simulate the full-load, half-load, and no-load condition, respectively. During FEA calculation the rotor is offset along $\mathrm{X}$ axis and $40 \%$ SAGE is simulated. The magnetic pull obtained in the electromagnetics module is then imported into the structural module to get the mechanical response.

During the experiment the velocity sensors are fixed on both the motor and the upright fixing plate (near the bearing). The HSPMSM is excited to rotate from $0 \mathrm{pm}$ to the rated rotating speed and then slow down again to $0 \mathrm{pm}$, to test both the vibration amplitude and the harmonic response.

\section{B. Results and Discussion}

UMPs and force density on rotor due to different running conditions are indicated in Fig.5 and Fig.6, while the deformations which reflect the vibration amplitudes are shown in Fig.7, and the harmonic response spectrum is indicated in Fig.8.

As indicated in Fig.5, the SAGE full load case has the maximum UMP, while the SAGE half load and the SAGE no load cases have the $2^{\text {nd }}$ and the 3 rd UMP, respectively. In the three normal cases the UMP is nearly zero. However, in reality it is very hard for a motor to strictly keep the air-gap symmetric, i.e., there is more or less a SAGE. Consequently, rotor UMP is actually rare to be zero.
Force densities on rotor for the 6 typical conditions indicated in Fig.6 suggest that the density rank order is the same as that of the MFD. In no load condition, the force density has only the radial component, while in loaded cases the force density will have both a radial and a tangential component at the same time. In addition, comparing Fig.5 with Fig.6 it can be inferred that the force density in the radial direction for the 3 normal conditions should be symmetrically distributed so that the general UMP can be zero. However, the occurrence of SAGE will break this kind of symmetry.

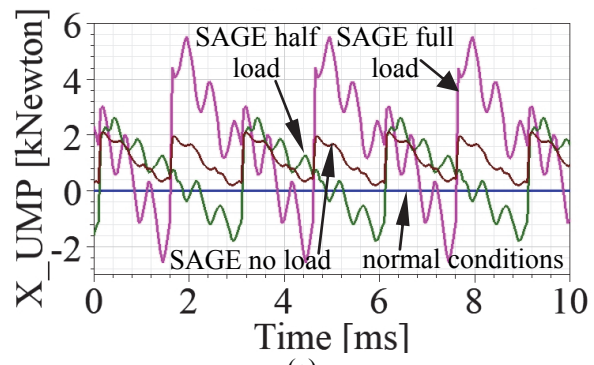

(a)

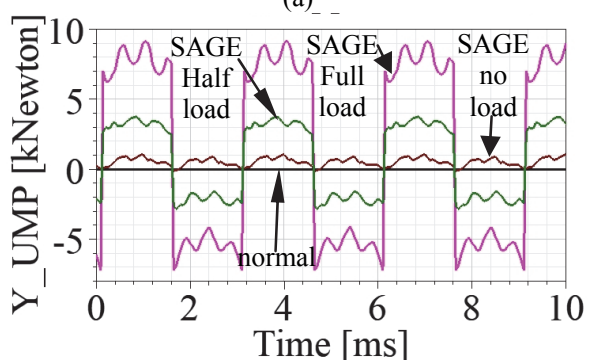

(b)

Fig. 5. UMPs on rotor in 6 typical running conditions (a) UMP in $\mathrm{X}$ direction, (b) UMP in Y direction

Rotor deformations due to the UMP and rotation shown in Fig. 7 generally indicate that the deformation amplitudes rank at the same order as the MFD. The SAGE full load case will cause the max deformation, while the normal no load condition brings in minimum deformation. On one hand, the increment of the load will increase the rotor deformation. On the other hand, the SAGE case will induce a larger deformation to the rotor than the normal condition when with the same load.

The harmonic response calculation result indicated in Fig. 8 shows that the rotor vibration will have the most intensified amplitudes at $3180 \mathrm{~Hz}$ and $6080 \mathrm{~Hz}$. However, the rated working frequency of the prototype HSPMSM is $1000 \mathrm{~Hz}$, which is far away from these two frequencies. Consequently, the prototype HSPMSM can work safely within the affordable vibration.

Actual vibrations according to the varied rotating speed (different frequency, as indicated in Fig.9) for normal noload, normal half-load, and normal full-load cases are indicated in Fig. 10 (since the prototype HSPMSM is not able to simulate SAGE currently due to the condition limit, we have not yet obtained the vibration response in SAGE cases). Fig.10 is actually the harmonic response result. 

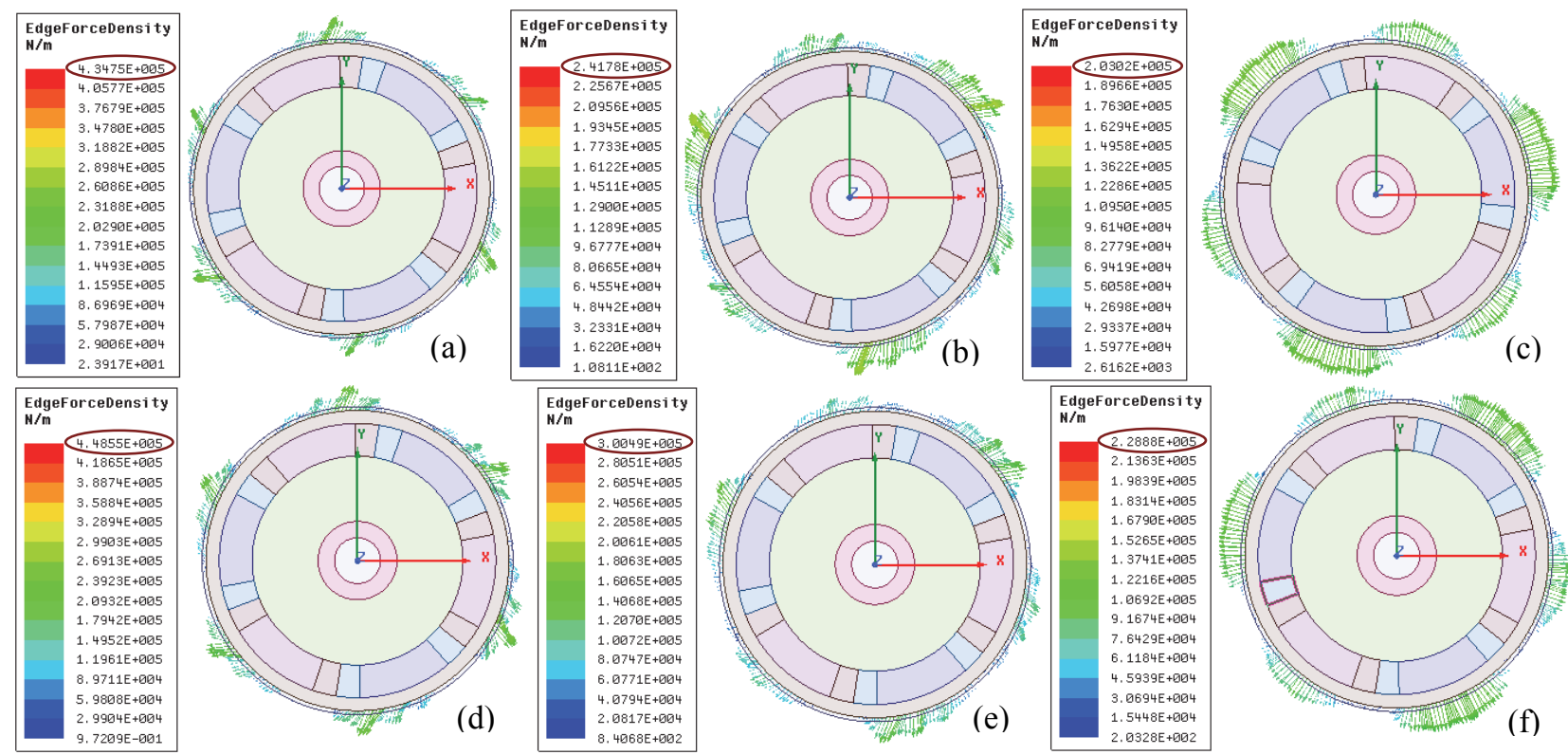

Fig. 6. UMP density on rotor in 6 typical conditions: (a) normal full load, (b) normal half load, (c) normal no load, (d) SAGE full load, (e) SAGE half load, and (f) SAGE no load.

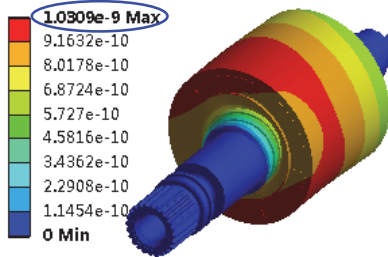

(a)

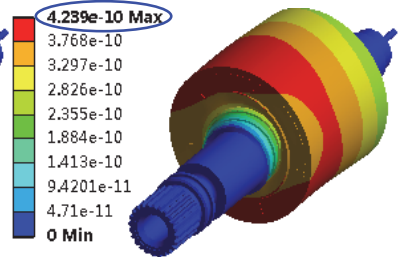

(b)

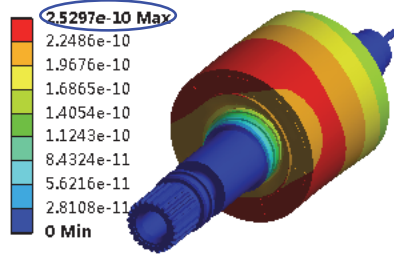

(c)

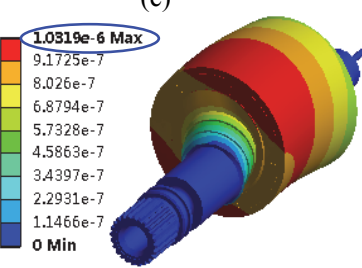

(e)

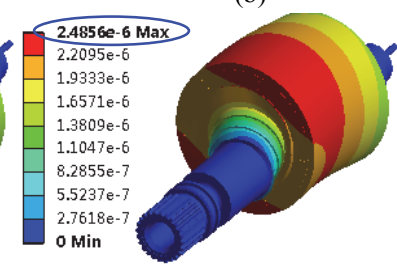

(d)

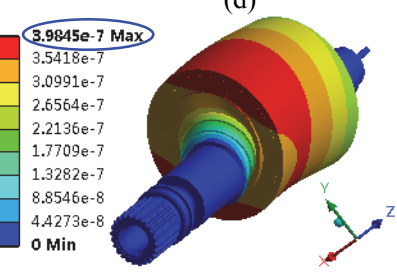

(f)
Fig. 7. Mechanical deformation due to UMP in 6 typical conditions: (a) normal full load, (b) normal half load, (c) normal no load, (d) SAGE full load, (e) SAGE half load, and (f) SAGE no load.

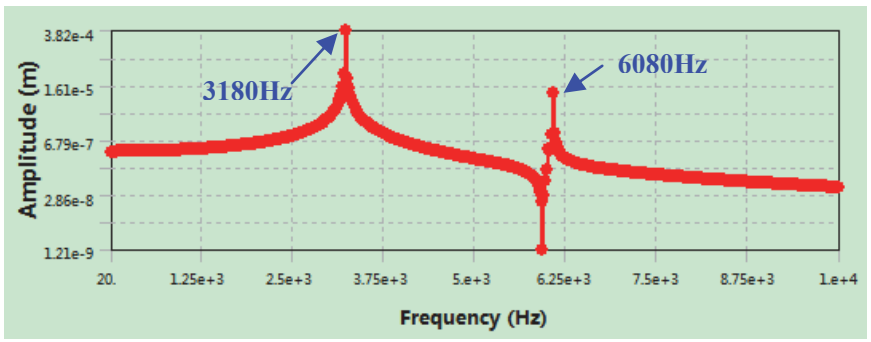

Fig. 8. Harmonic response of rotor

It is suggested from Figs. 9 and 10 that the vibration will obtain the maximum amplitudes when speeding up to the rated rotating speed and slowing down from the rated speed (at about 18000rpm to 19500rpm). Moreover, it still shows that the full load case will have the max vibration amplitude, while the no-load case has the minimum. This conclusion is in consistent with the previously theoretical and FEA results. Since the rated rotating speed is $20000 \mathrm{rpm}(1000 \mathrm{~Hz})$ which is less than $3180 \mathrm{~Hz}$ and $6080 \mathrm{~Hz}$, we do not get the full-band harmonic response. But it still confirms the security and validates the dynamic characteristic quality of the prototype HSPMSM since the maximum vibration amplitude is small (less than $4 \mathrm{~mm} / \mathrm{s}$ ).

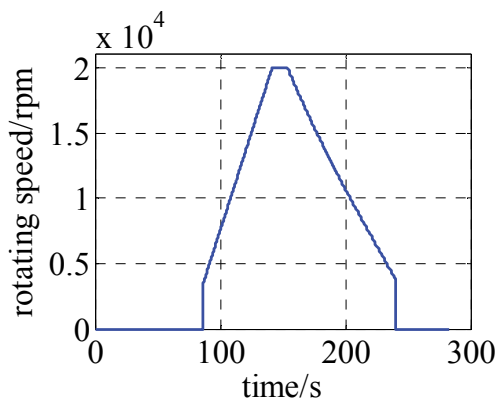

Fig. 9. Real-time rotating speed

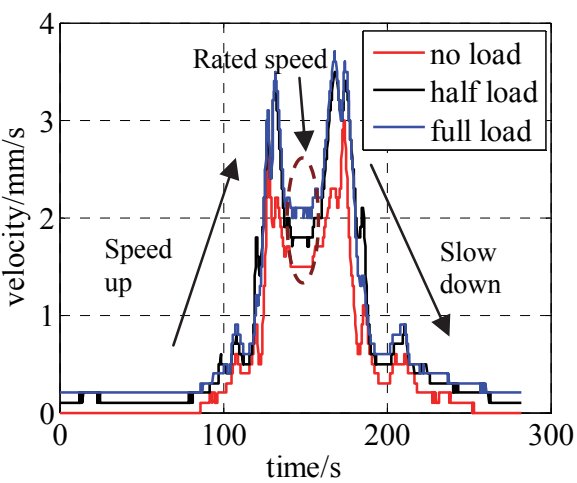

Fig. 10. Test vibration 


\section{CONCLUSION}

This paper studies on the UMP and the mechanical response on the rotor in 6 different typical running conditions, namely normal full-load, normal half-load, normal no-load, SAGE full-load, SAGE half-load, and SAGE no-load, in HSPMSM. Detailed UMP formulas, which can be employed for a quick force calculation and assessment, are deduced for the 6 running cases, respectively. It shows that in the SAGE full-load case the UMP and the mechanical response will have the peak value, while in the normal no-load condition the value will be the minimum.

In this paper the mechanical response including rotor deformation, radial vibration and harmonic response, is studied by FEA and experiment as well. It shows that the increment of the load will increase the rotor deformation and vibration. In addition, the SAGE case will induce a larger deformation to the rotor and cause a more intensive vibration than the normal condition when with the same load. The harmonic response analysis suggests that the rotor will obtain the max deformation amplitude at $3180 \mathrm{~Hz}$ and $6080 \mathrm{~Hz}$ which are far away from the rotor's working frequency $1000 \mathrm{~Hz}$. The prototype HSPMSM can work safely due to its qualified dynamic characteristics.

Since it is very hard to strictly keep the rotor centered with respect to the stator, each motor should more or less have a SAGE. Bearing wearing, stator core deformation, radial rotor offset, etc., can all lead to a typical SAGE case and consequently the rotor UMP and vibration will be significantly intensified. From this point of view, special care should be taken to check whether the bearings and the stator core are in good fit.

\section{ACKNOWLEDGMENT}

This work is in part supported by National Natural Science Foundation of China (51777074), Chinese Fundamental Research Funds for the Central Universities (2018YQ03), and the 3rd Top Youth Talent Support Program of Hebei Province ([2018]-27). The authors sincerely appreciate the PEMC group researcher Dr. Mahir Al-Ani's help in 3D modeling.

\section{REFERENCES}

[1] W. Cao, B. C. Mecrow, G. J. Atkinson, J. W. Bennett and D. J. Atkinson, "Overview of Electric Motor Technologies Used for More Electric Aircraft (MEA)," in IEEE Transactions on Industrial Electronics, vol. 59, no. 9, pp. 3523-3531, Sept. 2012.
[2] B. Dong, K. Wang, B. Han and S. Zheng, "High-speed permanent magnet motor with magnetic bearings: Multi-physics analysis, cooling design and experiment," 2016 19th International Conference on Electrical Machines and Systems (ICEMS), Chiba, 2016, pp. 1-4.

[3] K. Kawanishi, K. Matsuo, T. Mizuno, K. Yamada, T. Okitsu and K. Matsuse, "Development and Performance of High-Speed SPM Synchronous Machine," 2018 International Power Electronics Conference (IPEC-Niigata 2018 -ECCE Asia), Niigata, 2018, pp. 169-176.

[4] Y. Kataoka, M. Takayama, Y. Matsushima and Y. Anazawa, "Design of high torque PM vernier motor," 2016 19th International Conference on Electrical Machines and Systems (ICEMS), Chiba, 2016, pp. 1-6.

[5] P. S. Sangha and T. Sawata, "Design and test results for dual-lane fault-tolerant PM motor for safety critical aircraft actuator," 2015 IEEE Energy Conversion Congress and Exposition (ECCE), Montreal, QC, 2015, pp. 4055-4060.

[6] M. Lim, S. Chai, J. Yang and J. Hong, "Design and Verification of 150-krpm PMSM Based on Experiment Results of Prototype," in IEEE Transactions on Industrial Electronics, vol. 62, no. 12, pp. 7827-7836, Dec. 2015.

[7] J. Chen, Z. Wang, H. Hu and Y. Bai, "Numerical model for influence of unbanaced magnetic pull on the critical speed of motor-driven spindle," 2015 IEEE International Magnetics Conference (INTERMAG), Beijing, 2015, pp. 1-1.

[8] J. Ahn, J. Choi, C. H. Park, C. Han, C. Kim and T. Yoon, "Correlation Between Rotor Vibration and Mechanical Stress in Ultra-High-Speed Permanent Magnet Synchronous Motors," in IEEE Transactions on Magnetics, vol. 53, no. 11, pp. 1-6, Nov. 2017, Art no. 8209906 .

[9] S. Singhal, K. V. Singh and A. Hyder, "Effect of laminated core on rotor mode shape of large high speed induction motor," 2011 IEEE International Electric Machines \& Drives Conference (IEMDC), Niagara Falls, ON, 2011, pp. 1557-1562.

[10] C. Gan, J. Wu, M. Shen, S. Yang, Y. Hu and W. Cao, "Investigation of Skewing Effects on the Vibration Reduction of Three-Phase Switched Reluctance Motors," in IEEE Transactions on Magnetics, vol. 51, no. 9, pp. 1-9, Sept. 2015, Art no. 8203509.

[11] S. Shin, N. Kawagoe, T. Kosaka and N. Matsui, "Study on Commutation Control Method for Reducing Noise and Vibration in SRM," in IEEE Transactions on Industry Applications, vol. 54, no. 5, pp. 4415-4424, Sept.-Oct. 2018.

[12] C. Babetto, G. Bacco and N. Bianchi, "Synchronous Reluctance Machine Optimization for High-Speed Applications," in IEEE Transactions on Energy Conversion, vol. 33, no. 3, pp. 1266-1273, Sept. 2018.

[13] D. Kim, D. Hong, J. Choi, Y. Chun, B. Woo and D. Koo, "An Analytical Approach for a High Speed and High Efficiency Induction Motor Considering Magnetic and Mechanical Problems," in IEEE Transactions on Magnetics, vol. 49, no. 5, pp. 2319-2322, May 2013. 